Res Pública Revista de Historia de las Ideas Políticas

ISSN: 1131-558X

http://dx.doi.org/10.5209/rpub.68563

\title{
La filosofía del derecho de Schopenhauer en el debate de Carl Schmitt con Erich Jung (1912-1913)
}

\author{
Héctor del Estal Sánchez* \\ Recibido: 30 de marzo de 2020 / Aceptado: 26 de mayo de 2020
}

Resumen. El objetivo de este ensayo es presentar de un modo coherente el sentido y significado del artículo polémico de Carl Schmitt La filosofía del derecho de Schopenhauer fuera de su sistema filosófico (1913) como respuesta a Das Problem des natürlichen Rechts (1912) de Erich Jung. Primero, ofreceremos una imagen contextualizada de esta última obra atendiendo a sus deudas con la filosofía del derecho de Arthur Schopenhauer y, después, presentamos los argumentos esgrimidos por Carl Schmitt en ese texto y mostramos cuáles eran los rasgos generales del pensamiento schmittiano de aquellos años para poner de relieve, en último lugar, su significado filosófico como un ataque a la tecnificación junguianoschopenhaueriana del derecho y del Estado.

Palabras clave: Carl Schmitt; Arthur Schopenhauer; Erich Jung; derecho natural; positivismo jurídico.

\section{[en] Schopenhauer's Philosophy of Law in Carl Schmitt's debate with Erich Jung (1912-1913)}

\begin{abstract}
The aim of this essay is to offer coherently the significance and meaning of Carl Schmitt's polemical article Schopenhauer's Philosophy of Law Outside his Philosophical System (1913) as response to Erich Jung's Das Problem des natürlichen Rechts (1912). Firstly, we present a contextualized overall picture of this last work as paying attention to its debts with the philosophy of law of Arthur Schopenhauer, and then we present the arguments put forward by Carl Schmitt in that text, and finally we show what were the features Schmittian thought on those years in order to highlight its philosophical significance as an attack to Junguian-Schopenhauerian technification of law and State.
\end{abstract}

Keywords: Carl Schmitt; Arthur Schopenhauer; Erich Jung; Natural Law; Legal Positivism.

Sumario. 1. El positivismo jurídico y Das Problem des natürlichen Rechts de Erich Jung. 2. La crítica prima facie a la filosofía del derecho de Schopenhauer como respuesta a Erich Jung. 3. In gnosticismum, et technam. Lo divino en el mundo a través del derecho en el joven Carl Schmitt como resultado de una lectura católica de Däubler y Hegel. 4. Conclusión. Faustrecht: la profanación o negación del derecho en Schopenhauer y Jung. 5. Bibliografía.

Cómo citar: Del Estal Sánchez, H. (2020). La filosofía del derecho de Schopenhauer en el debate de Carl Schmitt con Erich Jung (1912-1913). Res Pública. Revista de Historia de las Ideas Políticas, 23(1), 175-188.

La mayoría de los "apóstoles" y "evangelistas" de Arthur Schopenhauer fueron juristas de formación y de profesión: Friedrich Dorguth, Johann August Becker, Adam von Doss, Carl Georg Bähr, Wilhelm Gwinner; todos provenían del ámbito jurídico. También Martin Emden, su "mejor amigo". Sin embargo, ninguno de ellos trató en profundidad su doctrina del derecho: no lo hicieron en sus obras ni tampoco en su correspondencia con el filósofo. Otras inquietudes fueron las que los llevaron a las orillas del pensamiento schopenhaueriano y otras fuerzas, las que los arrastraron a sus profundidades. Sin duda, que la filosofía del derecho de Schopenhauer estuviese aquejada por una falta de atractivo o de interés en los propios cimientos de su escuela puede causar cierta perplejidad si se tiene en cuenta la procedencia de sus integrantes; en cambio, cuando se recorre la acostumbrada senda de huellas temáticas que el influjo de su pensamiento ha dejado a partir la segunda mitad del siglo XIX, no suscita ninguna sorpresa descubrir que su filosofía del derecho -así lo atestigua el volumen de literatura sobre este tema- haya encontrado en comparación con otros tópicos de su pensamiento un eco significativamente menor entre las preferencias de los estudiosos.

Ahora bien, esto tiene su razón suficiente. Por una parte, el tratamiento que ésta recibe en sus obras es general y esquemático. ¿Qué podría hacer con la ordenación jurídica de este mundo "una filosofía que" -por usar una expresión de Thomas Mann- "tiene como meta la redención"? El propio Schopenhauer repite esto incansablemente: el reverso de su metafísica de la voluntad es una 
ética en cuyo extremo se halla una doctrina de la salvación; la vida pública y su dimensión jurídica poco tienen que ver con esto. En cualquier caso, el modesto papel que juega la doctrina del derecho en su filosofía no ha sido, por otra parte, la única causa que ha relegado este aspecto de su pensamiento a una posición casi anecdótica: incluso si la filosofía del derecho de Schopenhauer hubiese ostentado un papel central dentro de su sistema y hubiera estado en la posición de buscar algún tipo de difusión teórico-práctica, habría tenido que enfrentarse a otras Rechtslehren que dominaron el panorama filosófico-jurídico de su época; y los adversarios, sin duda alguna, hubiesen sido -de hecho lo fueron-formidables: G. W. F. Hegel en los años de "silencio" sobre su filosofía y J. von Stahl en los de su tardía fama.

A pesar de todo, en el cambio del siglo XIX al XX Schopenhauer y su filosofía del derecho irrumpen de un modo ocasional y sin previo aviso en algunas tesis doctorales, libros y artículos procedentes del mundo jurídico $^{1}$. Así, la indeleble impronta que el sabio de Frankfurt grabó en la vida cultural alemana durante este período sometido a su influencia directa tuvo su resonancia incluso en algunos trabajos de teóricos del Estado y del derecho de primer orden. En este sentido, destaca especialmente Die sozialethische Bedeutung von Recht, Unrecht und Strafe $\left(1874^{\mathrm{A}} ; 1908^{\mathrm{B}}\right)$, obra en la que Georg Jellinek -quien ya se había ocupado de Schopenhauer en su tesis doctoral ${ }^{2}$ - dedica unos nada desdeñables parágrafos centrales a discutir las nociones de justicia e injusticia en la filosofía schopenhaueriana; y también, con una temática afín, el pequeño artículo Die Rechtsphilosophie Arthur Schopenhauers außerhalb seines philosophischen Systems (1913) de Carl Schmitt.

El objetivo principal de este amplio trabajo es presentar de un modo coherente el sentido y el significado de este último texto, La filosofía del derecho de Schopenhauer fuera de su sistema filosófico, en el contexto del pensamiento filosófico-jurídico del joven Carl Schmitt. Para ello, primero ofreceremos una imagen general de la obra de Erich Jung Das Problem des natürlichen Rechts (1912) en el contexto de su época como un intento de elaborar a partir de la filosofía del derecho de

Desde el umbral del siglo xx hasta la década de los años treinta encontramos, fuera de los márgenes de la actividad científica de la Schopenhauer-Gesellschaft y de su anuario, los siguientes trabajos: E. Benda, Das Moralistische Recht Schopenhauers als Grundlage und Quelle für inductive Rechtsfindungen, Diss., Borna-Leipzig, 1913; R. Bovensiepen, "Die Rechts- und Staatsphilosophie Schopenhauers", en Zeitschrift für die gesamte Staatswissenschaft, 71 (1915), pp. 183-216; O. Damm, Schopenhauers Rechts-und Staatsphilosophie. Darstellung und Kritik, Halle, Kaemmerer, 1900; Th. von der Pfordten, Staat und Recht bei Schopenhauer, München-Berlin-Leipzig, J. Schweitzer, 1916; G. Stock, Abriß eines Systems der Erscheinungen des Rechtslebens an der Hand der philosophischen Methode Schopenhauers, Diss., Marburg, 1922; E. Warschauer, Schopenhauers Rechts- und Staatslehre, Kattowitz, Gebrüder Böhm, 1911; y K. Weigt, Die politischen und sozialen Anschauungen Schopenhauers, Diss., Erlangen, 1899. La razón de no indicar aquí los textos relativos a este tema en el Schopenhauer-Jahrbuch radica en mostrar que esta repentina, aunque excepcional atención a la filosofía del derecho de Schopenhauer aparece fuera de los círculos schopenhauerianos.

G. Jellinek, Die Weltanschauungen Leibnitz' und Schopenhauers. Ihre Gründe und ihre Berechtigung. Eine Studie über Optimismus und Pessimismus, Wien, Alfred Hölder, 1872.
Schopenhauer sin la metafísica que la sostiene una nueva doctrina del derecho natural. Después, mostraremos la naturaleza polémica del artículo schmittiano como respuesta a la obra de Jung, poniendo de relieve la crítica a la filosofía schopenhaueriana que se despliega en ese texto. A continuación, nos detendremos en la visión del derecho que Carl Schmitt mantiene en los años que rodean a la redacción del artículo, desde la cual se ilumina dicha crítica; y finalmente pondremos de manifiesto que el texto schmittiano constituye, en el fondo, un ataque a la tecnificación del Estado y del derecho como profanación de la naturaleza divina del mismo que se sigue tanto del "mito moderno" del individualismo como de la cosmovisión gnóstica de la filosofía schopenhaueriana.

\section{Elpositivismo jurídico y Das Problem des natürlichen Rechts de Erich Jung}

Erich Jung ${ }^{3}$ publica en 1912 un escrito titulado Das Problem des natürlichen Rechts. El sentido de este ensayo solo puede comprenderse a partir del contexto histórico al que responde: el positivismo jurídico heredero de Laband y Gerber. Éste, como doctrina filosófico-jurídica que trataba de depurar la reflexión sobre el derecho de toda consideración moral y política propia de las "quimeras" del lenguaje iusnaturalista, era un proyecto que tenía por objetivo, en última instancia, aclarar el significado de los términos y normas del derecho atendiendo únicamente a su lógica jurídica interna y a su aplicación en el ejercicio de la jurisprudencia. El éxito que desde el último tercio del siglo XIX cosechó el iuspositivismo fue fruto, principalmente, de su utilidad pragmática en el derecho privado: los profesionales del derecho encontraron en el positivismo jurídico una herramienta sumamente eficaz para la unificación de la interpretación de las leyes que permitía, a efectos prácticos, una mayor predictibilidad de los resultados de los procesos judiciales ${ }^{4}$. Sin embargo, tal y como se demostraría posteriormente en la época de la República de Weimar, el positivismo jurídico no lograría este mismo éxito al reflexionar sobre

Erich Jung (1866-1950) fue un jurista y filósofo del derecho cuyo pensamiento puede encuadrarse dentro de los límites de la llamada revolución conservadora y que acabaría convirtiéndose en un convencido militante del nacionalsocialismo. Hijo de un consejero del juzgado municipal de Mainz, en 1892 se doctoró en Derecho en la Universidad de Gießen. Tras su habilitación, ejerció como docente en las Universidades de Greifswald, Estrasburgo, Tubinga y Múnich; y a partir de 1921, como catedrático de Derecho Civil en la Universidad de Marburgo. Su producción intelectual no estuvo restringida únicamente al ámbito del derecho, sino que, como resultado de sus estudios de juventud en arte y filosofía, se extendió también a estos campos dando lugar a distintas publicaciones sobre política e historia del arte. En los años de la República de Weimar fue editor de la revista Deutschlands Erneuerung, de orientación pangermanista e inmersa en la völkische Bewegung; y en 1933 firmó la Declaración de los catedráticos de las Universidades y Colegios alemanes en favor de Adolf Hitler y del Estado Nacionalsocialista y entró a formar parte de la Liga de juristas alemanes nacionalsocialistas. (Cf. U. Jungcurt, Alldeutscher Extremismus in der Weimarer Republik. Denken und Handeln einer einflussreichen bürgerlichen Minderheit, Berlin/Boston, Gruyter, 2016, p. 175; E. Klee, Das Personenlexikon zum Dritten Reich. Wer war was vor und nach 1945?, Frankfurt am Main, Fischer, 2003, p. 291).

Cf. G. Balakrishnan, The Enemy. An Intellectual Portrait of Carl Schmitt, London/New York, Verso, 2000, pp. 13-14. 
otras cuestiones, propias del derecho público, como el problema de la soberanía o el de la constitución -temas a los que, precisamente, Schmitt prestará especial atención en las décadas de los veinte y treinta.

En este ambiente teórico, Das Problem des natürlichen Rechts de Jung es esencialmente una obra que trata de encontrar una salida a las limitaciones que, ya a comienzos del siglo xx, empieza a experimentar el positivismo jurídico en la práctica del derecho: la preocupación de Jung es que, bajo una interpretación y aplicación iuspositivista de las leyes, atendiendo exclusivamente a la norma legal, no siempre puede darse solución a la totalidad de casos que se presentan en los procesos judiciales. Por eso, el autor afirma: "En la práctica de la vida jurídica siempre surgen cuestiones que no pueden resolverse mediante [la] simple subsunción de los hechos probados bajo una norma jurídica dada. El dogma de la [total] completud del derecho o de la adecuación a la fuente [legal] de todas las sentencias [...] [es] un error" . Cuando estas situaciones se presentan, afirma el teórico del derecho, se suele apelar a nociones como "equidad" o "naturaleza de la cosa" como si éstas fuesen el último recurso para dar solución a una casuística de carácter excepcional. Sin embargo, advierte Jung, estos casos no solo son comunes, sino que, además, mediante esa apelación a categorías extrajurídicas indefinidas se disuelve la unidad del derecho, pues de su aplicación resulta una suerte de distinción entre "auténtico derecho" y "derecho equitativo" dependiendo de si un caso dado ha podido resolverse atendiendo estrictamente a la norma legal o no. Con el objetivo de suprimir esta indeterminación y bicefalia jurídica recurrirá Erich Jung a la filosofía del derecho de Schopenhauer.

Lo que está en juego aquí, según él, es la fundamentación misma del derecho: el problema de fondo consiste en que el positivismo jurídico, tal como se evidencia en su aplicación práctica, es incapaz de ofrecer claramente un "concepto del derecho y el fundamento de su validez" para dar con ello una respuesta satisfactoria a la pregunta por "el derecho de nuestro Derecho". Si esto es así, parece a todas luces necesario recurrir a una instancia extrajurídica para hacerlo ${ }^{6}$; y esa instancia la encuentra Jung en Schopenhauer. Ahora bien, el camino que lleva a la filosofía schopenhaueriana del derecho en este recurso no es directo: Jung no está dispuesto a deshacer los avances del propio positivismo jurídico ni tampoco los del positivismo filosófico ${ }^{7}$. El fundamento del derecho no puede encontrarse en un plano metafísico o trascendente, sino que ha de ser empírico-positivo. Sobre esta cuestión orbita toda la obra, en cuyo título se nos ofrece ya el término clave para entender que el

\footnotetext{
E. Jung, Das Problem des natürlichen Rechts, Leipzig, Duncker \& Humblot, 1912, p. 314.

6 Cf. Ibidem, p. 48. Jung no solo afirma esta necesidad, sino también su pertinencia metodológica y su uso habitual en la práctica jurídica: "Este recurso al fundamento más elevado [del derecho] es metodológicamente sencillo y permanece en el ámbito de la creación del derecho mediante la interpretación de enunciados de orden superior [Obersätzen]" (Ibidem, p. 49).

Jung sostiene, siguiendo la teoría del desarrollo histórico de Comte, que la ciencia del derecho (Rechtswissenschaft) se encuentra, en su época, en su estadio científico tras haber superado el teológico y el metafísico (Cf. Ibidem, p. 49-50).
}

peculiar sentido del proyecto junguiano guarda relación con su particular concepto de "derecho natural".

En efecto, la elección de la expresión natürliches Recht, en vez de la de Naturrecht nos coloca - a pesar de la sinonimia que en ocasiones se les ha atribuido ${ }^{8}$ - ante la distinción en un sentido moderno, de gran difusión en los círculos wolffianos del siglo XVIII, entre ius naturce y ius naturale ${ }^{9}$ : mientras que Naturrecht, entendido como ius naturce, designaba la doctrina de la deducción racional y a priori de los derechos y obligaciones del ser humano en cuanto tal (conforme a su esencia) y, con arreglo a ellos, de las relaciones jurídicas justas ${ }^{10}$; el $n a-$ türliches Recht, entendido como ius naturale, tenía por el contrario un carácter empírico, a posteriori, y estaba constituido por los principios jurídicos que se deducen como conclusión y epítome de un examen de las condiciones fácticas en las que se encuentra el ser humano dentro de sus circunstancias individuales en el seno de la sociedad civil. Este último, como señalaría hacia finales del siglo XVIII el ministro de justicia prusiano von Danckelmann ${ }^{11}$, era un instrumento útil para los magistrados, en un sentido prudencial y auxiliar, a la hora de dictaminar sentencias sobre casos que no caían dentro del espectro abarcado por las distintas leyes positivas.

De acuerdo con esta distinción y tal como se muestra a lo largo de la obra, Erich Jung apuesta claramente por una interpretación del derecho natural cercana a este segundo sentido de ius naturale: por una parte, éste debe cumplir, atendiendo al problema práctico que se toma como punto de partida en la obra, la función auxiliar que le atribuía von Danckelmann ${ }^{12}$. Pero, por otra, ha de ser capaz de desempeñar el mismo papel que el ius naturce a la hora de ofrecer una fundamentación filosófica del derecho; y esto tendría que hacerlo no a pesar de su carácter empírico-

La coincidencia de significado de ambas puede observarse, por ejemplo, en W. T. Krug, Allgemeines Handwörterbuch der philosophischen Wissenschaften, nebst ihrer Literatur und Geschichte. Nach dem heutigen Standpuncte der Wissenschaft. Bd. 3, Leipzig, Brockhaus, 1828 , p. 25.

9 Sobre la distinción y el contenido de ambas expresiones que aclaramos a continuación, cf. M. Hernández Marcos, "Conocimiento racional e historia. Sobre la relación entre derecho natural y derecho positivo en la Codificación Prusiana de 1794", en A. Prior Olmos (ed.), Estado, Hombre y Gusto Estético en la Crisis de la Ilustración, Valencia, Biblioteca Valenciana, 2003, pp. 171-179; N. N. Flack, Juristische Encyklopädie, auch zum Gebrauch bei akademischen Vorlesungen, Leipzig, Böhmberg, 1839, pp. 13-14 y 76-77; VV.AA., Rechtslexikon für Juristen aller teutschen Staaten enthaltend die gesammte Rechtswissenschaft. Bd. 9, Hrsg. J. Weiske, Leipzig, Otto Wigand, 1855, pp. 150-157.

10 A la primera parte de esta deducción se la ha denominado en la tradición iusnaturalista, ya desde Puffendorf, derecho natural absoluto, el cual indica estos derechos y obligaciones en un estado de naturaleza originario teniendo en cuenta únicamente la mera coexistencia de seres humanos; a la segunda, en cambio, se le dio el nombre de derecho natural hipotético, en el que se elaboraba el derecho privado y el de gentes bajo el supuesto de un segundo estado de naturaleza.

11 Cf. M. Hernández Marcos, "Conocimiento racional...", en A. Prior Olmos, (ed.), op. cit., pp. 171-172.

12 Tanto es así que el propio Jung entiende, de acuerdo con la fundamentación del derecho propuesta por él, que la decisión sobre la justicia o injusticia de cualquier caso que cayese fuera de la ley positiva "[...] recibiría quizás, como el mejor [posible], el nombre de «creación inductiva de derecho» [«induktive Rechtsfindung»] porque respecto al lado positivo, «jurídico-natural» [«natürrechtlichen»] del problema, sería una denominación [algo] indeterminada que, sin embargo, alcanza lo esencial" (E. Jung, op. cit., p. 43). 
positivo, sino precisamente gracias a él. La intención última de Jung es, por lo tanto, elaborar un derecho natural con tintes positivistas (en un sentido amplio del término) que no recuerde al proceder esencialista del viejo iusnaturalismo: "[...] aquí se realizará el intento" -insiste el autor- "de obtener el fundamento de la validez del derecho, o lo que es lo mismo, la idea de un derecho «naturalmente» vinculante [《natürlich» verpflichtenden Recht] totalmente empírico y realista, [a partir] de los hechos de la vida en común misma y de la interacción resultante de las [distintas] voluntades contrapuestas"13.

Erich Jung entiende así este derecho natural como una verdadera ciencia jurídica o del derecho: ésta "no es una ciencia pura, sino práctica" y, en ese sentido, no busca construir "edificios doctrinales", sino extraer los principios del derecho que se "sigue[n] [de] las consecuencias prácticas de la vida jurídica"14. En consecuencia, el derecho natural como ciencia debe proporcionar una razón suficiente objetiva ${ }^{15}$ que permita conocer de un modo adecuado por qué los magistrados deciden en uno u otro sentido en sus resoluciones cuando el caso juzgado cae fuera de la norma ${ }^{16}$ : el verdadero porqué que permite esta decisión sería, para Jung, el fundamento último del derecho, es decir, su concepto y la razón de su validez. Ahora bien: ¿cuál podría ser este fundamento del derecho "ahora que no creemos en fundamentos absolutos"17?

Al dar respuesta a esta última pregunta entra en escena Schopenhauer: el principio objetivo del derecho puede hallarse, según el autor, en los conceptos schopenhauerianos de derecho e injusticia; sin embargo, para elevar a fundamento del derecho estas nociones y, al mismo tiempo, satisfacer los requisitos que ha de cumplir una ciencia del derecho entendida en aquel sentido, Jung se ve obligado a hacer entrar en simbiosis el pensamiento de Schopenhauer y las hipótesis evolucionistas de Darwin. El proyecto junguiano de derecho natural solo resulta posible si se vacía de contenido metafísico la filosofía schopenhaueriana del derecho y se lo sustituye por contenidos provenientes de las teorías de las ciencias naturales y de la observación empírica de la sociedad. El andamiaje de esta articulación es sintetizado por Erich Jung del siguiente modo:

La distinción entre derecho [Recht] e injusticia [Unrecht] remite siempre a la categoría más amplia de la distinción entre bien [Gut] y mal [Böse $]$ en general ${ }^{18}$; cuando aquí se habla sobre la posibilidad de una derivación "natural" ["na-

13 E. Jung, op. cit., p. 55. Nótese que aquí Erich Jung se inspira en el concepto schopenhaueriano de voluntad; sin embargo, antes que entenderlo como la esencia íntima del mundo (y, en consecuencia, del ser humano) o como la clave interpretativa del mismo, lo toma únicamente -por utilizar una expresión schopenhaueriana- en su aspecto fenoménico o empírico como mero interés individual. Esto responde a la autoimpuesta exigencia metodológica empírico-positivista de Jung.

14 Ibidem, p. 2.

15 En última instancia, el natürliches Recht debe ofrecer los principios del derecho en virtud de los cuales se juzgan aquellos casos deduciéndolos científicamente de la experiencia "como conclusiones generalmente válidas, es decir, [como] conclusiones convincentes también para otros; un conocimiento objetivo, esto es, necesario según el principium rationis sufficentis cognoscendi" (Ibidem, p. 36).

16 Ibidem, p. 284.

17 Ibidem, p. 50.

18 Cf. infra, nota 27. türlichen"] de las experiencias éticas ${ }^{19}$ de la vida, es decir, puramente evolutiva al modo darwinista-schopenhaueriano y prescindiendo de recursos trascendentes, esto solo puede y debe ser una consideración introductoria en el conjunto de este trabajo, y no se otorga tanto valor a la peculiar forma de esta fundamentación de la ética, cuanto a la posibilidad que con ello se abre de una fundamentación del más acá, mundana y no metafísica de la validez misma del derecho ${ }^{20}$.

El punto de partida schopenhaueriano que adopta el jurista en este esquema es innegable: si se analiza la vida en comunidad, sostiene Jung, nos encontramos con que "[l]a lesión es [...] el primer fenómeno social"21. De esta manera, la relación natural que se da de un modo inmediato en la sociedad es fácticamente la injusticia, la cual es entendida como "una lesión de intereses; en general, algo que a causa de otro es sentido como desagradable [...] y que «puede rechazarse legítimamente mediante violencia sin cometer de nuevo injusticia», según la definición fundamental de Schopenhauer"22. De este factum social es de donde surge propiamente el derecho:

La reacción de la víctima contra la lesión es el fenómeno fundacional de la vida jurídica; [...] [es decir], que el individuo interesado no acepta tranquilamente ciertas acciones u omisiones de algún otro enfrentado a él, sino que mediante el uso de la fuerza reacciona contra ellas con la convicción de que el oponente debería [aceptar y] soportar esta violencia y que él, quien la ejerce, puede contar con el apoyo de los otros miembros de la sociedad ${ }^{23}$ no involucrados en esa acción, y con que no [se le considerará por ello] un enemigo de la $\mathrm{paz}^{24}$.

19 Ha de notarse que aquí Erich Jung hace valer "experiencia ética" como un concepto práctico análogo al de "conciencia" en la filosofía de Schopenhauer (cf. A. Schopenhauer, El mundo como voluntad y representación. Volumen I, trad. Roberto Rodríguez Aramayo, Madrid, F.C.E./Círculo de Lectores, 2003, p. 439; Los dos problemas fundamentales de la ética, trad. Pilar López de Santa María, Madrid, Siglo XXI, 2009, p. 262 y Metafisica de las costumbres, trad. Roberto Rodríguez Aramayo, Madrid, Trotta, 2001, p. 102). Tanto en la "experiencia ética" junguiana como en la "conciencia" schopenhaueriana es donde se pone de manifiesto el valor o significado ético de las acciones humanas. Con ello, para ambos autores, se abre la posibilidad de dar una definición a los conceptos de derecho e injusticia previa a todo derecho positivo y, con ello, fundar un derecho natural: "Esta significación puramente ética es la única que tienen lo justo y lo injusto para los hombres en cuanto seres humanos, no en cuanto ciudadanos de un Estado. Dicha significación de lo justo y lo injusto subsistiría también en el estado de naturaleza, al margen de cualquier ley positiva. Ella constituye el fundamento y el contenido de lo que se ha dado en llamar derecho natural y que sería mejor denominar derecho ético, ya que no abarca el padecer, la realidad exterior, sino que se ciñe al obrar y al conocimiento de su voluntad individual que ese obrar ocasiona en el hombre, conocimiento que recibe el nombre de conciencia [Gewissen]" (A. Schopenhauer, Metafisica... op. cit., p. 101).

20 E. Jung, op. cit., pp. 314-315.

${ }_{21}$ Ibidem, p. 65. Esta noción de injusticia encuentra su reconocida inspiración en la definición dada por Schopenhauer como una afirmación de la voluntad tal que sobrepasa los límites del cuerpo propio hasta llegar a la negación de la voluntad en el cuerpo de los otros (Cf. A. Schopenhauer, El mundo... Volumen I, op. cit., p. 432).

22 E. Jung, op. cit., pp. 91-92.

23 Jung entiende este apoyo como reconocimiento de la lesión producida a la víctima y como «ayuda» en el ejercicio de la violencia física en la legítima defensa (Cf. Ibidem, p. 65).

24 Ibidem, p. 90. Para Jung, asumir la definición schopenhaueriana de la injusticia no implica únicamente conceder al filósofo del pesimismo que ésta se da fácticamente en un primer término, sino que ésta es 
Lo que ocurre en este fenómeno originario del derecho no es, para Erich Jung, esencialmente distinto de lo que sucede cuando un juez dicta sentencia sobre aquellos casos no subsumibles bajo la ley positiva: en ambas situaciones tiene lugar una experiencia ética no solo individual, sino también colectiva conforme a la cual se juzga con aprobación o reprobación una determinada acción libre ${ }^{25}$. Con ello, Jung establece una familiaridad, una «unicidad» de todos los fenómenos éticos respecto a los cuales el derecho se comportaría como la especie con el género. Por ello afirma: "[d]e naturaleza ética es todo enunciado, concepto, etc., que dice algo sobre cómo debemos [sollen] comportarnos; que compara nuestras acciones con [las de] otros, y [que] contiene una aprobación o desaprobación de ellas" ${ }^{\prime 26}$.

Pero ¿qué es lo que se aprueba o desaprueba tanto en la ética como en el derecho?, es decir, ¿cuál es el criterio conforme al cual se juzga? Aquí Erich Jung vuelve a recurrir al análisis positivo del comportamiento social; y el contenido del deber ético, en un sentido general, es explicado atendiendo al conjunto de relaciones empiricas entre distintos individuos interesados:

[...] un cierto comportamiento de los individuos hacia los demás -afirma Jung- es reconocido por éstos como favorable para ellos y, por lo tanto, por principio se [lo] considera deseable [wünschenswert]. Un comportamiento divergente [abweichendes] de los individuos se considera perjudicial para los demás y, por lo tanto, para el conjunto; $\mathrm{y}$, en consecuencia, indeseable [nicht wünschenswert ${ }^{27}$.

Ahora bien, el sello de cientificidad de esta base ética del derecho lo certifica el darwinismo, que desde el

asimismo el prius teórico en la filosofía del derecho, mientras que la justicia o el derecho serían, en cambio, el posterius (Cf. A. Schopenhauer, El mundo... Volumen I, op. cit., p. 437-438; Los dos problemas... op. cit., p. 260 y Metafisica... op. cit., p. 98).

25 Jung insiste en este último rasgo, necesario para que se dé cualquier experiencia ética: "[Solo mediante] el convencimiento de que la voluntad humana es libre adquiere aquella distinción [entre justicia e injusticia] el contenido característico de un enunciado sobre asuntos morales: que un comportamiento debería ser [sein sollte]; [mientras] que el otro no debería ser [nicht sein sollte]. Tal juicio solo tiene sentido en relación con un centro de causas volente determinado por motivos; en el lenguaje de Schopenhauer: en relación con procesos que se encuadran bajo el principium rationis sufficentis agendi" (E. Jung, op. cit., p. 53).

26 Ibidem, p. 51. La diferencia específica entre ética y derecho sería que la primera atañe únicamente a la conciencia; mientras que el segundo implica coacción externa (Cf. Ibidem, p. 53).

27 E. Jung, op. cit., p. 52. Debido a la reducción del concepto de voluntad a mero interés individual, la mirada "interior" de la que la conciencia [Gewissen] schopenhaueriana se sirve para remitir las acciones humanas a los conceptos de lo bueno y lo malo en general (a saber, el significado de las mismas bajo el prisma de la tesis de la identidad de todos los individuos como voluntad de vivir) carece, para Jung, de significado: la "experiencia ética" junguiana se sirve de la observación empírica "exterior" como único indicador del valor ético de las acciones. En consecuencia, Jung considera que los rasgos fenoménicos atribuidos por Schopenhauer a las acciones buenas y malas son el único termómetro ético válido; y le sigue cuando éste afirma que las acciones que no obstaculizan o favorecen la voluntad de los otros despiertan "la estima puramente objetiva [...] de los demás" (El mundo... Volumen I, op. cit., p. 460); "mientras que, por el contrario, el mal comportamiento", caracterizado por desfavorecer o dañar la voluntad de los demás, "[...] no deja de suscitar aversión y menosprecio en los testigos que tengan noticia de tal actuación" (A. Schopenhauer, Metafísica... op. cit., p. 131). ámbito las ciencias naturales corrobora y explica tanto el origen como la evolución y conversión de estos juicios subjetivos en normas objetivas: el instinto que empuja a los individuos a la vida social y a una "reglamentación moral" de la misma sería una extensión histórico-evolutiva de las dinámicas propias de la vida familiar natural del ser humano ${ }^{28}$; primero, hacia la tribu y, solo después, hacia círculos más amplios de la sociedad hasta llegar a la "nación" y, finalmente, al conjunto de la humanidad. De esta progresiva ampliación de las relaciones éticas surgiría el derecho: inicialmente como derecho privado; expandiéndose después con la aparición del derecho público y, ya alcanzado un estado elevado de desarrollo de la cultura, con la del derecho de gentes.

Desde esta perspectiva, Jung admite una evolución de la "cultura jurídica" en la que puede variar tanto lo "beneficioso" para cada sociedad concreta como los medios de los que el derecho dispone para juzgarlo como tal, para protegerlo y para promoverlo ${ }^{29}$. Con ello, queda abierta la posibilidad de una mejora paulatina del cumplimiento del fin último del derecho: la protección de los intereses individuales y, mediante ella, la salvaguarda del interés general de mantener la paz ${ }^{30}$. Esta meta del derecho -afirma Jung usando una expresión de Jellineklo convierte en un "mínimum ético [...]: [el derecho es] objetivamente el mínimo existencial de las normas éticas; subjetivamente, el mínimo de la actividad vital y de la conciencia moral que busca ser promovido por los miembros de la sociedad" ${ }^{\prime 3}$. Sin la respuesta a la injusticia que supone el derecho como reprobación organizada, coercitiva y reglamentada de todas aquellas relaciones humanas que, a ojos de la sociedad, no deberían ser, la vida en común y la existencia del ser humano resultarían imposibles.

Contra esta fundamentación del derecho heredera de Schopenhauer que Erich Jung expone en Das Problem des natürlichen Rechts, Carl Schmitt presentará La filosofía del derecho de Schopenhauer fuera de su sistema filosófico. La crítica que allí hace el joven jurista se centrará en mostrar la imposibilidad del proyecto junguiano: para Schmitt, el derecho no puede ser justificado o fundamentado sobre la base de las tesis schopenhauerianas; menos aún cuando éstas han sido aisladas de su sistema metafísico.

\footnotetext{
Cf. E. Jung, op. cit., p. 92.

Cf. Ibidem, p. 67.

Cf. Ibidem, pp. 67, 86-87.
}

31 E. Jung, op. cit., pp. 66-67. Aquí Jung comparte con Schopenhauer también la concepción minimalista e instrumentalista sobre el papel del derecho positivo y del Estado en la que ambos son definidos de acuerdo con su utilidad: para los dos autores el derecho es el "mínimo existencial" sin el cual la vida en sociedad y la paz resultarían imposibles. La afinidad con Schopenhauer es evidente: para evitar la guerra de todos contra todos, la imposición injusta del interés individual, del egoísmo, es necesaria la construcción, aplicación y salvaguarda de un ordenamiento jurídico que atienda a aquel derecho natural o ético al que apuntan ambos autores; y tales tareas corresponden al Estado. El derecho positivo y el Estado que lo hace valer son el único remedio frente al Faustrecht (Cf. A. Schopenhauer, $P a$ rerga y paralipómena. Volumen II, trad. Pilar López de Santa María, Madrid, Trotta, 2009, p. 259 y El mundo como voluntad y representación, volumen II, trad. Roberto Rodríguez Aramayo, Madrid, F.C.E./Círculo de Lectores, 2003, p. 575). 
2. La crítica prima facie a la filosofía del derecho de Schopenhauer como respuesta a Erich Jung

La lectura de la obra de Jung planteó al joven Carl Schmitt la siguiente cuestión: ¿pueden las tesis fundamentales de la filosofía del derecho de Schopenhauer servir para fundamentar un sistema filosófico-jurídico? ${ }^{32}$ Ya en 1912 había en sus diarios: "Nota a Jung, página 111 (Derecho natural): [...] siempre y cuando no se haya leído algo como a Schopenhauer, el derecho es, conforme a la ley, un asunto bastante fácil de tratar"33. Si tenemos en cuenta esta noticia, no es difícil imaginar que su respuesta fue negativa. Para Carl Schmitt - esta es la conclusión de La filosofía del derecho de Schopenhauer fuera de su sistema filosófico (1913)- la filosofía del derecho schopenhaueriana no es más que "un ornamento casual y estilístico" ${ }^{\text {34 }}$ para su sistema metafísico, apenas consistente dentro de éste y completamente inútil fuera de él. Este es el planteamiento general del artículo polémico: la doctrina del derecho de Schopenhauer no solo sería incapaz de fundamentar correctamente el derecho, sino que también habría enturbiado la comprensión sobre la esencia del derecho de Erich Jung en su intento de refundar desde una nueva perspectiva metodológica el derecho natural.

Estas dos últimas cuestiones, que para Carl Schmitt están íntimamente ligadas, son articuladas en su crítica a Das Problem des natürlichen Rechts mediante un análisis destructivo de las nociones rectoras de la filosofía del derecho de Schopenhauer y del método seguido para llegar a ellas. Schmitt dirigirá sus esfuerzos a poner en cuestión la eficacia de la via negationis en la filosofía del derecho schopenhaueriana destacando la insuficiente definición del derecho que resulta de ella: la crítica explícita del joven jurista consistirá en demostrar que la doctrina del derecho de Schopenhauer incurre, desde el comienzo, en una petitio principii que conlleva graves problemas tanto a la hora de establecer los límites entre justicia e injusticia con arreglo a su concepto como a la de abordar la cuestión básica del origen de la legitimidad de las leyes y del Estado; situación que se agrava, finalmente, cuando Schmitt descubre una tricefalia de principios en la fundamentación del derecho ofrecida por Schopenhauer.

Así, al comienzo de su artículo, Carl Schmitt llama la atención sobre la tarea misma de la filosofía del derecho: ésta debe consistir en ofrecer al conocimiento la esencia del derecho, pues solo conforme a ella puede fundamentarse el derecho mismo ${ }^{35}$. Tal es la tarea que Erich Jung ha tratado de realizar apoyándose tanto en las tesis centrales de la filosofía del derecho de Schopenhauer como en su método; y, por lo tanto, estos dos aspectos son los que, de acuerdo con Carl Schmitt, deben someterse a juicio en primer lugar. Esto lo hace Sch-

\footnotetext{
32 Cf. C. Schmitt, "Schopenhauers Rechtsphilosophie außerhalb seines philosophisches Systems", Monatsschrift für Kriminalpsychologie und Strafrechtsreform X, 1, abril, 1913, pp. 27, 28 y 31.

33 C. Schmitt, Tagebücher. Oktober 1912 bis Februar 1915, hrsg. Ernst Hüsmert, Berlin, Akademie Verlag, 2005, p. 36.

34 Cf. C. Schmitt, "Schopenhauers Rechtsphilosophie...", op. cit., p. 31 .

35 Cf. Ibidem, p. 27.
}

mitt acudiendo a su raíz y examinándola: los conceptos de justicia y derecho en la filosofía de Schopenhauer y el modo según el cual son deducidos. Sobre esto, Carl Schmitt señala que la via negationis es un método de investigación legítimo, también a la hora de esclarecer la esencia del derecho y de suministrar un concepto del mismo. Ahora bien, Schmitt advierte que esta aproximación apofática a la definición del derecho debería ampliar el alcance epistémico del concepto ofrecido, y no traducirse en una mera "paráfrasis" negativa de lo que éste no es, la cual, en definitiva, no proporcionaría ningún aumento de conocimiento. Sin embargo, cuando Schopenhauer define el derecho como "lo que cabe hacer sin cometer injusticia" ${ }^{36}$, para el joven jurista queda claro que no se ha ampliado nuestro conocimiento sobre el derecho, sino que -este será el núcleo temático que trataremos en el siguiente punto de nuestro trabajo- se "niega" ${ }^{37}$ su esencia.

Una vez esclarecido lo concerniente a la tarea de la filosofía del derecho y su metodología, lo relevante para Carl Schmitt es mostrar las razones por las que el método negativo, aunque virtualmente válido, no da frutos en Schopenhauer. El argumento central de Schmitt es que Schopenhauer toma por fundamento aquello sobre lo que precisamente recae el onus probandi ${ }^{38}$ : su filosofía del derecho solo sería "una traducción de las intuiciones jurídicas básicas común e inalterablemente aceptadas"39 al lenguaje de su metafísica de la voluntad. Esta "subrepción" de la carga probatoria en la filosofía del derecho de Schopenhauer ha sido realizada, asegura Carl Schmitt, al reemplazar el contenido de los conceptos de injusticia y de derecho por el del juego entre afirmación y negación de la voluntad.

Al convertir en punto de partida la definición de la injusticia como afirmación de la voluntad de vivir de un individuo hasta el extremo de la negación de la voluntad en otro, y al deducir negativa y consecuentemente de esta definición la justicia y el derecho como un acto de negación de esa negación, lo que hace Schopenhauer, según Carl Schmitt, no es otra cosa que trasladar el foco, en lo concerniente a estas nociones jurídicas, desde aquella voluntad de vivir general, una y la misma en todos los fenómenos como esencia íntima del mundo, a la voluntad individual; y con ello, el centro de gravedad del derecho se traslada hacia la individualidad ${ }^{40}$ : en la filosofía del derecho de Schopenhauer, en el fondo, no se daría valor a la voluntad de vivir, sino al individuo. Mas con este paso, lo que haría el filósofo del pesimismo es presuponer un derecho individual a la no negación en vez de deducirlo de la intuición fundamental de su sistema (la identidad esencial de todos los fenómenos como expresión de la voluntad de vivir). A partir de este momento, en su crítica, Carl Schmitt ya hace gala del método que tanto éxito le proporcionará en años posteriores: el análisis del caso límite y de la excepción. La pregunta que dirige Schmitt a Schopenhauer es aquí la de "por

\footnotetext{
36 Cf. C. Schmitt, "Schopenhauers Rechtsphilosophie...", op. cit., pp. 27-28 y 30 .

37 Cf. Ibidem, p. 28

38 Cf. Ibidem, p. 29

39 Cf. Ibidem, p. 30

40 Cf. Ibidem, p. 28
} 
qué una negación tal de la voluntad individual tiene que ser, como tal, injusticia" ${ }^{\prime 1}$. Para el jurista, en la filosofía del derecho de Schopenhauer no puede encontrarse la respuesta, pues el derecho a la no negación no ha sido deducido a partir del concepto de voluntad de vivir, sino construido y presupuesto artificialmente junto a él.

Carl Schmitt advierte, además, que la consecuencia inmediata de la falta de una verdadera fundamentación en este punto es que las definiciones de derecho e injusticia dadas por Schopenhauer no facilitan "ningún tipo de indicio acerca de dónde está el límite entre la afirmación y la negación" "42. De nuevo, el caso límite es el criterio para el análisis de Schmitt: la mera existencia de un individuo en el espacio y en el tiempo, su impenetrabilidad, supone una negación de la voluntad de otro individuo, pues "impido que otro esté donde yo estoy"43. Sin embargo, que este caso límite no sea relevante en modo alguno para el derecho, es decir, que no implique injusticia a pesar de ser, efectivamente, una negación de la voluntad de otro individuo es una cuestión que para Carl Schmitt queda igualmente sin respuesta en la filosofía del derecho de Schopenhauer y viene a evidenciar que el derecho individual a la no negación -el cual, por otra parte, resulta ser a todas luces mucho más restringido de lo que se desprende directamente tanto de los conceptos de afirmación y negación como de su relación con los de derecho e injusticia en Schopenhauer- es a fin de cuentas una construcción jurídica, no el resultado de una verdadera "deducción"; y, como tal, requiere precisamente de fundamentación para demostrar su pretendida justicia ${ }^{44}$. En definitiva, los argumentos ofrecidos por Schopenhauer no pueden, en modo alguno, ser el fundamento de un sistema filosófico-jurídico, pues "las palabras afirmación y negación" -sostiene el joven Schmitt- "contienen ya en sí los elementos normativos en torno a cuya fundamentación gira todo" ${ }^{\text {"45; }}$ contienen la norma, mas no la prueban.

Mostrada la petitio principii que subyace a la doctrina schopenhaueriana del derecho y la falta de una verdadera fundamentación en la misma, se pone de manifiesto igualmente su incapacidad para dar cuenta de la legitimidad del Estado y de su derecho a la punición. Por una parte, si en la filosofía del derecho de Schopenhauer lo que está en cuestión es siempre y en todo momento la voluntad individual, no puede darse "en sentido estricto ninguna injusticia contra el Estado o la comunidad"46; y lo que es peor, se pone en tela de juicio el derecho punitivo mismo: ¿cómo podría fundamentarse el derecho del Estado a castigar si el derecho es concebido como una negación de la negación de la voluntad, y la voluntad lesionada es siempre y en todo caso la de un individuo, la de quien padece injusticia, y no la de su familia ni tampoco la de la sociedad? Aquí Carl Schmitt analiza, de nuevo, un caso límite: el de la pena de muerte $^{47}$. Desde la perspectiva de Schopenhauer-argumenta

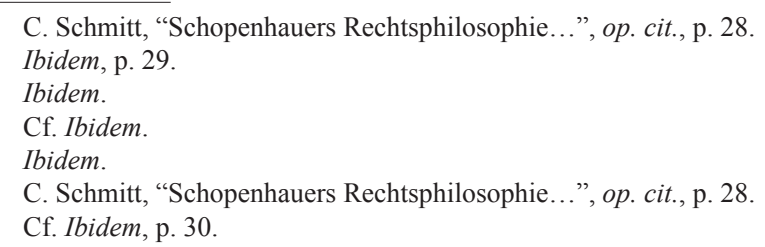

Schmitt- cuando el Estado ejecuta la pena capital, su derecho solo podría ser fundamentado con una multiplicación de entes, pues debe postularse una voluntad que no sea la individual, la cual, en el caso juzgado, resulte ser la lesionada y, como consecuencia, dé lugar a un derecho de coacción acorde a tal voluntad. Sin embargo, esto seguiría sin resolver el problema: ¿por qué el derecho a ejecutar la pena de muerte lo ostenta únicamente el Estado y no la familia de la víctima, cualquier individuo que viese lesionada, por ejemplo, su "voluntad de seguridad" o cualquiera otra voluntad pensable que se pudiese postular ${ }^{48}$ ?

De todo esto se desprende para Carl Schmitt que la verdadera fundamentación del derecho tiene que ser, por necesidad, otra bien distinta a la ofrecida por Schopenhauer. Tanto es así, que el propio filósofo del pesimismo habría procedido en sus escritos utilizando el concepto de derecho (Recht) en contextos en los que su contenido no podría en modo alguno deducirse como una negación de la injusticia. Esto se evidenciaría, precisamente, en el tratamiento que Schopenhauer da al derecho penal y a la legitimidad del Estado para aplicarlo: en él se pone de manifiesto que la mayor debilidad de la filosofía schopenhaueriana del derecho es que se basa en una "heterogeneidad" de principios ${ }^{49}$. El problema ya no solo reside aquí en que el fundamento del derecho no pueda ser la negación de la negación de la voluntad, sino que entran en conflicto entre sí otras dos fundamentaciones divergentes para el Estado y el derecho. Por una parte, la "legalidad" del derecho penal y la autoridad del Estado para administrarlo se basarían, según Schopenhauer, en la necesidad de una institución protectora, en el anhelo de seguridad y en la utilidad del derecho penal y del Estado para garantizarla $^{50}$. Y, sin embargo, por otra parte, el filósofo del pesimismo situaría al mismo tiempo esta legalidad y legitimidad en el contrato $^{51}$.

Llegados a este punto, Carl Schmitt considera que la tricefalia de principios (negación de la negación de la voluntad de vivir, utilidad y contrato) colocada a la base del derecho y de la legitimidad del Estado es la perfecta expresión del fracaso de Schopenhauer en su intento de elaborar una verdadera filosofía del derecho. Desde el punto de vista del joven jurista, el filósofo del pesimismo solo ha sido capaz de ofrecer una explicación "puramente factual" del origen del derecho, pero no una verdadera fundamentación del mismo $\mathrm{s}^{52}$. Justamente por eso, y aunque tal explicación etiológica pueda tener cierto valor, Carl Schmitt considera que el proyecto de erigir un sistema filosófico-jurídico utilizando como apoyo tesis schopenhauerianas, tal y como Jung pretende, es imposible.

\footnotetext{
Cf. Ibidem.

Cf. Ibidem, p. 31

50 Este modo de fundamentar la legitimidad del Estado en una antropología pesimista ha sido analizado posteriormente por Carl Schmitt en El concepto de lo político, Madrid, Alianza, 1998, pp. 87-90.

51 Estas dos fundamentaciones diversas de la legitimidad del derecho penal y el Estado en la filosofía de Schopenhauer pueden verse, respectivamente en: A. Schopenhauer, El mundo... Volumen I, op. cit., pp. 441-444 y 445-448.

52 Cf. C. Schmitt, "Schopenhauers Rechtsphilosophie...", op. cit., p. 31.
} 
Junto a esta crítica general a la filosofía del derecho de Schopenhauer, extensible a Erich Jung en todos sus matices, en el artículo de Carl Schmitt se encuentran, finalmente, unas breves observaciones sumamente reveladoras, que abren la puerta a una interpretación más profunda del texto y que adquieren una importancia excepcional a la hora de interpretar la posición del teórico del derecho y el sentido último de su crítica: nos referimos a dos comentarios relativos a las propuestas de Schopenhauer y Jung sobre la naturaleza negativa del derecho y a la concepción del Estado bajo el punto de vista instrumental.

Respecto a lo primero, Schmitt rechaza que, incluso desde una perspectiva schopenhaueriana, el derecho pueda ser entendido como un nihil privativum, como algo puramente negativo. Incluso si se aceptase que el derecho solo podría darse a causa de la injusticia, resultaría evidente que la mera existencia de la injusticia no implica por sí sola la del derecho: si el derecho es la negación de una negación (Negation einer Verneinung), ésta es, como tal, una afirmación, un acto positivo ${ }^{53}$. Para Carl Schmitt la positividad del derecho no puede ser anulada ni siquiera desde la fundamentación que para él ha ideado Schopenhauer al definirlo como algo derivado. En lo concerniente a lo segundo, a la concepción del Estado como institución protectora cuya legitimidad estaría basada en su utilidad, concluye que "una institución con tal objetivo" es "algo desdeñable y desprovisto de dignidad moral" $" 54$ : el verdadero derecho del Estado (por mucho que la utilidad pueda ser considerada su "explicación factual") se gesta, para Schmitt, precisamente en los motivos relacionados con la repugnancia, censura y protesta contra los argumentos instrumentales aducidos por Schopenhauer para fundamentar el derecho penal y el Estado.

Detrás de estas dos últimas críticas se esconden las razones filosóficas de mayor peso e importancia para un Carl Schmitt que lee el mundo y el derecho con las lentes del catolicismo, la filosofía hegeliana y la poesía de Däubler. Esta lectura, implícita en el texto, es la que amplía el calado del artículo polémico contra Erich Jung y Arthur Schopenhauer, y lo transforma no solo en un análisis destructivo de sus filosofías del derecho, sino en una manifestación temprana de su oposición a la tecnificación del mismo y del Estado ligada tanto a la cosmovisión moderna del mundo y su individualismo como a su alternativa gnóstico-schopenhaueriana.

\section{In gnosticismum, et technam. Lo divino en el mundo a través del derecho en el joven Carl Schmitt como resultado de una lectura católica de Däubler y Hegel}

La pregunta sobre qué significado y alcance filosóficojurídico tiene el artículo polémico sobre Schopenhauer y Jung no puede encontrar respuesta sin atender previamente a esta otra: ¿quién era el Carl Schmitt de 1913? Esta cuestión, sumamente compleja, no se deja responder con una breve caracterización. Sin duda, no nos en-

\footnotetext{
Cf. Ibidem, p. 29

54 C. Schmitt, "Schopenhauers Rechtsphilosophie...", op. cit., p. 31.
}

contramos ante el Schmitt de la distinción amigo-enemigo -aunque ya en esta época no le faltasen enemigos que combatir-, ni tampoco ante el que interroga incansablemente por la esencia de la soberanía; antes bien nos encontramos con un teórico del derecho que prefigura o atisba algunas de las intuiciones fundamentales que años más tarde plasmará, entre otros trabajos, en obras como Romanticismo político (1919), Teología política (1922) o Catolicismo romano y forma politica (1923). Si tuviésemos que encontrar la respuesta a aquella pregunta en las palabras del propio Carl Schmitt, la aseveración de que él siempre fue "un lego católico" 55 saldría rápidamente a nuestro encuentro; también, la sucinta autodescripción retrospectiva de su pensamiento en estos años: "Joven (1907-1918): Neokantismo y granprusianismo deshegelianizado con impronta Guillermina" ${ }^{56}$. Lo cierto es, sin embargo, que estamos ante una figura polifronte que es capaz, sin tornar el rostro, de dirigir al mismo tiempo su mirada tanto hacia las vanguardias artísticas del expresionismo como hacia la fría ciencia del derecho neokantiana, de contemplar henchido de religiosidad la lejana aurora boreal de la poesía de Däubler y, a la vez, de escudriñar con desprecio los apetitos del individuo burgués; que idea racionalmente cuál es el camino para que el espíritu objetivo se aposente en Berlín mientras asiste lleno de admiración y sobrecogido a la impresión que en su corazón produce la función del obispo de Roma; que reconoce la crisis, el mal y la inmediatez de su tiempo y en el mundo en la misma medida que está convencido de la necesidad de salvación. Neokantismo, hegelianismo, catolicismo, antiliberalismo, la influencia de las vanguardias y los versos impregnados de gnosticismo de Theodor Däubler; todos estos elementos son los que se presentan, de un modo impuro, en su pensamiento juvenil. Atendiendo al conjunto, cada una de estas tendencias no solo convive, sino que coopera simbióticamente sin conflicto, aunque no sin tensión, tanto en sus escarceos literarios como en sus ensayos científicos -y quizás, precisamente debido a esto, la relación que mantuvo el joven jurista con cada una de ellas por separado no pudo ser sino conflictiva. A la sombra del primer conflicto mundial que está a punto de cernirse sobre Europa, ésta es la realidad interior en la que Carl Schmitt vive, piensa y escribe.

Si buscamos un hito que acote las lindes del terreno en el que se mueve Carl Schmitt en 1913 cuando escribe La filosofía del derecho de Schopenhauer fuera de su sistema filosófico, ese es el trabajo que le valdría posteriormente la habilitación en la Universidad de Estrasburgo: El valor del Estado y el significado del individuo (1914). Allí cristalizan de un modo ordenado y encuentran una articulación consistente aquellas direcciones intelectuales y espirituales que desembocan en una determinada concepción del derecho y del Estado a la luz de la cual la crítica a Schopenhauer y Jung adquiere un calado teórico de mayor relevancia.

\footnotetext{
C. Schmitt, Glossarium. Aufzeichnungen aus den Jahren 1947 bis 1958, Berlin, Duncker \& Humblot, 2015, p. 283.

56 Citado según: H. Orestes Aguilar, Carl Schmitt, teólogo de la política, México, F.C.E., 2001, p. 11
} 
Tanto el artículo sobre Schopenhauer como el escrito de habilitación se nutren de sus experiencias vitales y formativas o científico-filosóficas comprendidas entre 1910 y 1914. Entre las primeras, la toma de contacto con las vanguardias estéticas ya en 1910 tuvo, más allá de las incursiones schmittianas en el terreno literario con Schattenrisse (1913) -obra que no estaba, por lo demás, desprovista de crítica-, una resonancia significativa en su producción científica como teórico del derecho. Desde el punto de vista de la crítica sociocultural, este impulso de carácter estético deja notar su eco en la animadversión de Carl Schmitt hacia el espíritu y el statu quo de su época: nos referimos, fundamentalmente, al dominio de la técnica y de la economía, y a la Bürgerlichkeit. En este sentido, el contacto con las vanguardias acentuó un cierto espíritu de contracultura que en el joven Schmitt se rebela contra

la era de la máquina, de la organización, la era mecanicista [...], la era que muestra a través de los objetos de su anhelo y entusiasmo lo que le falta, cuya cultura, tal y como fácticamente gobierna, ha llevado hasta el final en los distintos campos de la vida espiritual, del arte y de la ciencia, la idea expansiva de empresa, de economía dineraria, de la técnica, del arte de la puesta en escena $[\ldots]^{57}$.

En esta época vivaracha, el estilo de vida burgués, aplaudido como libre e individualista, está sometido, en realidad, a los estrechos límites del mero interés "práctico" regido por relaciones económicas tecnificadas y burocratizadas: el burgués alemán ordena su vida de acuerdo a múltiples fines y la adorna con un -mezquino para Carl Schmitt- "buen gusto", pero carece completamente de alma. Esta impresión encontrará, en el ocaso del primer conflicto mundial, un profundo análisis en Romanticismo político (1919) y, de un modo más inmediato, se articulará filosóficamente en una crítica al individualismo como el "mito" moderno sobre el que se asienta el liberalismo y que concibe un tipo humano guiado únicamente por meros fines subjetivos. Semejante complejo teórico -como veremos algo más in extenso en el desarrollo de nuestra exposición-será centro de los ataques schmittianos.

Acompañando esta crítica, surgen también de este influjo expresionista otras dos intuiciones que guiarán la reflexión filosófico-jurídica de Carl Schmitt sobre el derecho, el Estado y la política: por una parte, aparece una preocupación por el lenguaje y el poder decisivo mítico, si se quiere- de los símbolos ${ }^{58}$; y, por otra, la convicción de que detrás de los fenómenos -también de los fenómenos jurídicos- hay una estructura esencial que está más allá de la superficie que a simple vista se manifiesta $^{59}$. De un modo análogo a lo que hicieron la

\footnotetext{
57 C. Schmitt, El valor del Estado y el significado del individuo, trad. Celestino Pardo, Madrid, Centro de Estudios Políticos y Constitucionales, 2014, pp. 5-6.

58 Cf. J. Meierhenrich y O. Simons, "«A Fanatic of Order in an Epoch of Confusing Turmoil»: The Political, Legal, and Cultural Thought of Carl Schmitt", en J. Meierhenrich y O. Simons (eds.), The Oxford Handbook of Carl Schmitt, New York, Oxford University Press, 2016, pp. 42-44.

59 Cf. E. Kennedy, Constitutional Failure. Carl Schmitt in Weimar, Durham/London, Duke University Press, 2004, pp. 38-40.
}

deriva cubista del expresionismo en el arte pictórico y Däubler en la expresión lingüística, Schmitt tratará en estos años, especialmente en torno a 1913-14, no solo de alcanzar discursivamente lo verdadero y esencial que subyace a la vida jurídica, sino de presentarlo -como un sacerdote- mediante un lenguaje filosófico-jurídico propio en sus escritos. Así, en esta educación sentimental de principios de siglo se situaría entonces la prehistoria de su reiterada preocupación científica de ir a la verdadera raíz de las nociones políticas y jurídicas ${ }^{60}$ : la exigencia que el joven Schmitt plantea -y que puede rastrarse fácilmente hasta sus consideraciones de Teología Política-de "cientificidad", de ir a la "radicalidad de los conceptos", se configura en estos años como una tentativa de elaborar una "verdadera ciencia" del derecho que alcance "lo ideal" y "lo esencial". Esta perspectiva se opone frontalmente a la expresión de aquella época tecnificada en los campos científico y filosófico: principalmente el iuspositivismo, pero también los intentos de elevar la sociología, la historia o la psicología de los conceptos jurídico-políticos al rango de verdadera ciencia del derecho. Carl Schmitt considera que estos modos de aproximarse al derecho son "prácticos", útiles para el político, el estadista y el abogado, pero en modo alguno para el filósofo del derecho ${ }^{61}$.

En este punto es donde distintas corrientes filosóficas comienzan a forjar alianzas improbables y sorprendentes en el pensamiento del joven Carl Schmitt, y el paso por la Universidad de Estrasburgo en los años 19081912 es fundamental para una de ellas. La universidad de esta ciudad alsaciana se había convertido, como Heidelberg o Friburgo, en un bastión anti-iuspositivista y se alineaba con la filosofía del derecho neokantiana ${ }^{62}$. En concordancia con aquella exigencia de "radicalidad" legada por las vanguardias, Carl Schmitt encontró con agrado la invitación a una ciencia pura del derecho en el neokantismo, que se orientaba filosóficamente hacia el esclarecimiento epistemológico de los conceptos del derecho, de sus criterios universales, y centraba sus esfuerzos en la abstracción del contenido de las normas jurídicas ${ }^{63}$.

Acompañando a esta afinidad electiva entre las intuiciones asimiladas del expresionismo y el neokantismo, se halla también la confesión católica de Schmitt, concordante en cierto modo con la filosofía neokantiana del derecho en la medida en que ésta sostenía (frente a un iuspositivismo que reducía el derecho a un producto fáctico del poder del Estado soberano) la idea de que una "ley elevada" debía existir con anterioridad al establecimiento por parte del Estado de las leyes positivas;

60 Cf. E. Kennedy, op. cit., pp. 40-42.

61 "Es necesario poner el acento en que nada más que argumentos, no fines, tendencias o corrientes temporales, son susceptibles de refutación. La ciencia está por sus conceptos en otro mundo; en oposición abierta con la vida fáctica. «Vivir es en realidad no filosofar, filosofar en realidad no vivir», dijo (en un fragmento del año 1799) Fichte, que no sólo fue un gran filósofo sino también un hombre de vida verdaderamente activa" (C. Schmitt, El valor ... op. cit., p. 8).

62 Cf. J. W. Bendersky, Carl Schmitt. Theorist for the Reich, New Jersey, Princeton University Press, 1983, p. 9.

${ }^{63}$ Cf. R. Emerson, State and Sovereignty in Modern Germany, New Haven, Yale University Press, 1928, pp. 160 y ss. Esto es especialmente claro en: C. Schmitt, El valor... op. cit., pp. 10-11). 
y esto lo hacía, además, sin recaer en el vetusto derecho natural ${ }^{64}$. Sin embargo, el catolicismo de Schmitt, por lo demás siempre heterodoxo ${ }^{65}$, le impedía abrazar por completo el neokantismo. El obstáculo era aquí, por una parte, su formalismo ${ }^{66}$ : si bien el ideal de una ciencia filosófico-jurídica que atendiese únicamente a la lógica interna del derecho y de las normas con independencia de los hechos empíricos era el caballo de batalla contra el iuspositivismo de su tiempo, la solución neokantiana le parecía que estaba, no obstante, desprovista de vida. Ahora bien, más allá de la cuestión de este formalismo (que se opone a la convicción schmittiana de que en el derecho existe un contenido sustancial que no es meramente formal ni tampoco un ideal regulativo), lo que, por otra parte, el católico Schmitt no podía aceptar bajo ningún pretexto era el individualismo que se hallaba a la base de los distintos proyectos neokantianos en filosofía del derecho. Esto es lo que subyace en última instancia y verdaderamente a las distintas críticas que Schmitt dirige en El valor del Estado... contra Cohen, Stammler y Natorp $^{67}$. Una pasión católica antiliberal es la que, en el fondo, aleja al joven jurista del neokantismo.

Todos estos elementos afines, pero todavía estériles y difícilmente compatibles en el alma del joven jurista, necesitaron de una síntesis, de una mediación. Las intuiciones legadas por las vanguardias, la aproximación neokantiana a la ciencia del derecho y su ideal, y la animadversión católica al individualismo moderno encontraron, en Carl Schmitt, su componente aglutinador en una lectura católica de Däubler y Hegel.

La obra de Däubler Nordlicht, que ya fascinó a Schmitt en 1910, podría haberse contado aquí como otro elemento más de su educación sentimental expresionista ${ }^{68}$; sin embargo, la honda impresión que le causó el poema, con su dualismo y su gnosticismo -advertido, solo a medias, en aquel entonces ${ }^{69}$ - fue fundamental para él, tal y como recordaba en 1946:

${ }_{64}$ Cf. J. W. Bendersky, op. cit., p. 10; J. Trejo-Mathys, "Neo-Kantianism in the philosophy of law: its value and actuality", en N. de Warren y A. Stati (eds.), New Approaches to Neo-Kantianism, Cambridge, Cambridge University Press, 2015, pp. 150-151.

65 Sobre la polivalente relación biográfica de Carl Schmitt con el catolicismo, así como sobre la dificultad de caracterizar las resonancias de su confesión personal en su obra, cf. R. Mehring, "A «Catholic Layman of German Nationality and Citizenship»? Carl Schmitt and the Religiosity of Life", en J. Meierhenrich, y O. Simons (eds.), op. cit., pp. 73-95; C. Ruiz Miguel, "Estudio preliminar", en C. Schmitt, $\mathrm{Ca}$ tolicismo romano y forma política, Madrid, Tecnos, 2000, pp. xv-xx.

66 Cf. E. Kennedy, op. cit., pp. 70-71. Una discusión acerca de hasta qué punto la filosofía del derecho neokantiana es formalista la encontramos en: J. Trejo-Mathys, "Neo-Kantianism...", en op. cit., pp. 161 y ss.

67 Cf. C. Schmitt, El valor... op. cit., pp. 41-48. No obstante este distanciamiento respecto del neokantismo ya en 1914, S. L. Paulson ha señalado acertadamente la coincidencia de Schmitt con algunos planteamientos de Hans Kelsen en "Hans Kelsen and Carl Schmitt. Growing Discord, Culminating in the «Guardian» Controversy of 1931", en J. Meierhenrich y O. Simons (eds.), op. cit., pp. 512-518.

68 Cf. C. Schmitt, Ex captivitate salus. Experiencias de la época $1945-$ 1947, trad. Anima Schmitt de Otero, Madrid, Trotta, 2010, p. 50

69 Algunos intérpretes de Carl Schmitt, no sin encontrar fundamentos en distintos pasajes de sus obras y, sobre todo, de sus diarios, no dudan en situar su confesión religiosa en el gnosticismo en vez de en el catolicismo (cf. R. Groh, Carl Schmitts gnostischer Dualismus. Der boshafte Schöpfer dieser Welt hat es so eingerichtet (...), Berlin, Lit Verlag, 2014, pp. 29-48); sin embargo, nosotros coinci-
El espíritu reconcilia y acalla el mundo. [...] Aquel verso $[. .$.$] es el último verso de la gran epopeya de Däubler,$ Das Nordlicht, su fin, su conclusión. [...] [Durante] mucho tiempo se me ocultó el auténtico sentido histórico-filosófico de la aurora boreal. En un trabajo muy juvenil, del año 1916, le di una interpretación cristiana y Däubler, en su generosidad inmensa, lo aceptó sin protesta. Hoy día sé que la aurora boreal luce en el brillo pálido de la gnosis de la humanidad ${ }^{70}$.

La relevancia de la lectura católica de Nordlicht se deja ver de inmediato en el motto de El valor del Estado y el significado del individuo: "Lo primero es el mandato [Gebot], los hombres vienen después". Este lema sintetiza la idea fundamental que rige el pensamiento filosófico-jurídico del Schmitt de esta época, a saber: que "el Derecho precede al Estado" $"$ y al individuo. La articulación de esta idea resulta impensable sin la adopción del dualismo de inspiración gnóstica de Däubler y su superación mediante una lectura con tintes hegelianos del dogma cristiano de la Trinidad. Veamos esto con mayor detenimiento.

Si la epopeya de Däubler establece un dualismo entre el mundo sensible (plagado, a su vez, de otros dualismos, de polos contrapuestos) y la aurora boreal, el espíritu que, bajo la lectura de Carl Schmitt, transfigura salvíficamente la Tierra $^{72}$; el dualismo fundamental que atraviesa El valor del Estado... es el de poder-derecho como dos potencias contrapuestas, la una terrena y la otra divina. El poder, en esta obra de Schmitt, es entendido como una expresión de las fuerzas de la Tierra: éste es el poder desnudo encarnado en las instituciones temporales (que precisamente por su condición sensible, se demuestran local e históricamente cambiantes), pero es también el "poder del homicida" y "descansa al final en la violencia" lo que acontece en la inmediatez de su ámbito no es sino el conflicto, las antítesis irresolubles fruto de intereses y fines subjetivos. Desde este punto de vista, es fácil comprender cómo Carl Schmitt puede interpretar el liberalismo de su época como una expresión de este reino terreno en el que solo puede darse el desorden a causa de la continua lucha de fines subjetivos e individuales.

Frente al poder, tan lleno de fuerza como caótico, Carl Schmitt identifica el paraíso y el orden en el derecho. Éste es algo "extra-humano, sobrehumano, intemporal" 74 cuya esencia es "norma pura, valiosa en sí"75, un mandato heterónomo; en otras palabras: "el Derecho no es voluntad, sino norma, no es una orden personal sino un mandato frente al cual el hombre como objeto del mundo real viene después. [...] [E]s un pensa-

dimos con Reinhard Mehring en que ésta es una interpretación un tanto especulativa que no está libre de entrar en conflicto filosófica y biográficamente con la figura de Carl Schmitt (Cf. R. Mehring, "A «Catholic Layman ...»", en J. Meierhenrich y O. Simons (eds.): op. cit., pp. 85)

70 C. Schmitt, Ex captivitate... op. cit., p. 51

C. Schmitt, El valor ... op. cit., p. 8.

72 Cf. J. L. Villacañas Berlanga, Poder y conflicto. Ensayos sobre Carl Schmitt, Madrid, Biblioteca Nueva, 2008, pp. 35-39.

73 Cf. C. Schmitt, El valor... op. cit., pp. 13-14.

74 Ibidem, p. 23

75 Ibidem, p. 4. 
miento abstracto" "76. Sin embargo, el derecho, entendido como norma, como un valor elevado que está sobre el mundo y que es anterior a la ley positiva, deviene impotente, pues él solo empieza "donde el Poder es indiferente o superfluo"77 y "no puede querer ejecutarse a sí mismo" 78 .

Este dualismo, sin duda empapado del carácter gnóstico de la poesía de Däubler, es con el que se abre $E l$ valor del Estado...; y resulta fácil ver en él la similitud entre el carácter de un Dios creador, demiúrgico, encarnado en el poder, en las potencias terrenas, y el de un Dios logos, salvador, concretado en la figura contrapuesta del derecho, en el espíritu representado por la aurora boreal. Sin embargo, en este punto la lectura católica de Däubler es fundamental. El derecho tiene ciertamente aquel carácter divino, ordenador y salvífico, pero la promesa de salvación no implica por el momento una "salvación de la humanidad por el espíritu y en el espíritu"79. En otras palabras: a pesar de que -tal y como asegura Carl Schmitt citando otro verso de Däubler- "[1]a eternidad no se alcanza por la propia escalera" ${ }^{80}$, esto no implica una completa negación o disolución en la nada del reino terreno y del poder. Lo que aquí entra en juego y se opone firmemente al gnosticismo de Däubler es la convicción católica de que Dios no puede abandonar el mundo ${ }^{81}$, de que la Tierra y la humanidad no son radicalmente malos ${ }^{82}$.

Ahora bien, para que el dualismo däubleriano que da forma a la filosofía del derecho schmittiana se armonice con su catolicismo, es decir, para que no termine por ser, precisamente, gnosticismo, se impone la necesidad de una instancia mediadora entre los dos polos opuestos de aquel dualismo, entre el mundo sensible y la aurora boreal, que garantice una continuidad entre ambos y que haga de la Tierra también un lugar en el que el derecho, lo divino, esté presente. Esta instancia no es para Carl Schmitt otra sino el Estado.

De la contraposición entre norma y mundo empírico nace la posición del Estado como punto de transición entre un mundo y otro. En él, como piedra angular, se pasa del Derecho, como puro pensamiento, al Derecho como fenómeno terrestre. El Estado es por eso una forma jurídica, cuyo sentido está exclusivamente en la tarea de realizar el derecho, forzando un estado en el mundo exterior que se corresponda en la medida de lo posible con las exigencias

Ibidem, p. 28.

Cf. Ibidem, p. 22.

Ibidem, p. 27.

79 C. Schmitt, Ex captivitate..., op. cit., p. 52. Solo con la lectura de Proudhon en 1938, se percataría Schmitt de ese resultado gnóstico de Nordlicht (Cf. Ibidem, p. 53).

80 C. Schmitt, El valor... op. cit. p. 24.

81 Cf. J. L. Villacañas Berlanga, op. cit., pp. 21-25.

82 Así en Catolicismo romano... (1923): “[...] a diferencia de la teoría protestante de la total corrupción de la naturaleza humana, el dogma [católico] habla solo de una lesión, debilitamiento u oscurecimiento de la naturaleza humana [...]" (C. Schmitt, Catolicismo... op. cit., p. 9). Esta idea se presenta ya antes en el artículo de 1917, La visibilidad de la Iglesia (traducción castellana: C. Schmitt, "La visibilidad de la Iglesia. Una reflexión escolástica" trad. Román García Pastor, Daimon. Revista internacional de filosofia 13 (1996), pp. 11-18 [https://revistas.um.es/daimon/article/view/8421]). del pensamiento jurídico sobre el comportamiento de los hombres singulares y la organización del mundo exterior ${ }^{83}$.

Así es como Carl Schmitt elude el gnosticismo sobre el que se erige su filosofía del derecho: la fe católica es, a fin de cuentas, una fe hegeliana. Dios, el espíritu, el derecho, no puede abandonar el mundo porque está presente en él como espíritu objetivo ${ }^{84}$. En otras palabras: se realiza en y mediante lo que no es él. La filosofía de Hegel es la corriente silenciosa que discurre bajo $E l$ valor del Estado... y la que establece las directrices de esta mediación: para Schmitt el Estado supera la negación del derecho representada por el poder desnudo conservando éste como instrumento para la realización de aquél; hace del poder un poder con derecho y convierte el mundo empírico, terreno, en el "medium" del derecho a través del derecho positivo:

La antítesis es entre Derecho y Estado, no entre Derecho e individuo, y la afirmación hegeliana de que el Derecho es la unidad entre la impersonal, supra-empírica regla y el individuo, debe modificarse en el sentido de esta disertación. El Derecho positivo es la unidad entre una impersonal, supraempírica regla y el Estado. El individuo empírico queda al margen. El Estado como poder, y por ello no Derecho, está frente al Derecho precisamente para realizarlo ${ }^{85}$.

Esta lectura hegeliana de sus propias posiciones es asimismo una lectura católica de Hegel. El Estado, como garante de la ordenación conforme al derecho del poder que él mismo es, garantiza en un sentido fuerte la presencia de Dios en el mundo; y esta dialéctica encuentra su perfecta expresión cristiana en el dogma de la Trinidad ${ }^{86}$ : el Dios demiúrgico del mundo terrestre, del poder, queda transfigurado en Dios Padre; el Dios logos, la aurora boreal que porta el mensaje de la salvación, del derecho, en Dios Hijo; mientras que el Estado, como permanente recordatorio de ese mensaje en la Tierra e impulsor de su cumplimiento en la lucha contra el pecado, puede ser pensado análogamente al Espíritu Santo. Estas tres figuras del mismo Dios, del Dios Uno, son las que alejan por completo a Carl Schmitt del gnosticismo; y así, las lecturas católicas de Däubler y Hegel no pueden pensarse la una sin la otra en su filosofía juvenil.

\footnotetext{
C. Schmitt, El valor ... op. cit. p. 38.

84 Cf. J. L. Villacañas Berlanga, op. cit., p. 16.

85 C. Schmitt, El valor... op. cit. p. 60. Precisamente por esta tarea, el verdadero Estado, para Carl Schmitt, no puede ser otro sino uno imperial, que emule el modelo de Roma, de la Iglesia católica (Cf. Ibidem, p. 32).

86 Una posición, sin duda menos hegeliana, pero afín a esta lectura, la expresa Schmitt en Catolicismo romano y forma política como sigue: "Del mismo modo que el dogma tridentino desconoce el desgarramiento protestante entre naturaleza y gracia, así el Catolicismo tampoco entiende todos esos dualismos entre naturaleza y espíritu, naturaleza y entendimiento, naturaleza y arte, naturaleza y máquina y sus pathos cambiantes. La síntesis de las antítesis permanece ajena al Catolicismo, lo mismo que el contraste entre la forma vacía y la materia informe; así, la Iglesia católica es algo distinto de aquel «tercero superior» (por lo demás siempre ausente) de la filosofía alemana de la naturaleza y de la historia. Con la Iglesia no congenia la desesperación de la antítesis ni el orgullo ilusionado de sus síntesis" (C. Schmitt, Catolicismo... op. cit., p. 13-14). Sobre la afinidad entre el dogma de la Trinidad y la dialéctica hegeliana en el pensamiento de Carl Schmitt, encontramos observaciones muy esclarecedoras en: J. L. Villacañas Berlanga, cp. cit., pp. 20-22.
} 
Tal visión del derecho, del poder y del Estado, en la que este último asegura la continuidad entre ambos, es la que convierte la pasión católica antiliberal de Schmitt en una posición filosófica: ¿qué lugar puede ocupar el individuo en este esquema? Desde el punto de vista de la filosofía del derecho, que piensa sus conceptos -he aquí el poso vanguardista y neokantiano- en el elemento ideal y puramente abstracto sin la mácula empírica de los hechos, el individuo solo puede pensarse en relación con el Estado, el verdadero sujeto del "ethos jurídico", en cuanto instrumento de la realización del derecho:

Del concepto de Estado como tarea, se sigue que el significado del individuo dentro del Estado hay que medirlo igualmente por una tarea. Para el Estado el individuo como tal tan solo es el casual portador de una tarea esencial, de la concreta función que debe cumplir. Por principio no puede tener el Estado a nadie por irremplazable o insustituible. Y explica mucho mejor el sentido del Estado, el fenómeno universal del funcionario público, de personalidad fungible, que su desvalorización a simple negotiorum gestor de la sola importante "personalidad"

El Estado, en cuanto medio para la realización del derecho en la Tierra, como garante de la presencia del espíritu en ésta, lo que hace en relación con el individuo es imprimirle, mediante el derecho positivo y la coerción, un fin objetivo. Esto se opone a la concepción del individualismo moderno y su correlato político, el liberalismo: el valor y significado del individuo no puede residir en sus fines subjetivos ni tampoco el Estado y su derecho puede fundarse mediante la lucha y armonización de tales fines. Solo al servicio del fin objetivo de la tarea estatal de encarnar el derecho, y no persiguiendo sus fines individuales, puede el individuo obtener significado y valor ${ }^{88}$. Así, "la grandeza de los hombres está en la grandeza de su tarea y su ejecución" ${ }^{89}$, es decir, "el individuo sólo alcanza significación, en tanto ejecute una función" ${ }^{90}$ dentro del orden estatal para la realización y cumplimiento del derecho en la Tierra. En este sentido " $[\mathrm{t}]$ odo lo que la filosofía puede hacer es subrayar que todo Poder sin derecho carece de sentido y que la persona, por poderosa que sea, es en tanto tal insignificante. Lo que vaya más allá, son preguntas del político, en parte psicológicas y caracteriológicas, en parte pedagógicas, puramente técnicas" ${ }^{\prime 91}$.

\section{Conclusión. Faustrecht: la profanación o negación del derecho en Schopenhauer y Jung.}

Solo teniendo todo esto en cuenta es posible valorar en su justa medida la crítica a Schopenhauer y Jung. Toda la argumentación que Schmitt esgrime en La filosofia del derecho de Schopenhauer fuera de su sistema filosófico se asienta en esta concepción del derecho y del Estado; la cual, aunque subyacente en el artículo, no puede encontrar expresión -como indicábamos al comienzo de

\footnotetext{
C. Schmitt, El valor ... op. cit. p. 60.

Cf. J. L. Villacañas Berlanga, op. cit., p. 31

C. Schmitt, El valor ... cp. cit. p. 63

Ibidem, p. 64

Ibidem, p. 75.
}

nuestra exposición- por sus límites formales como trabajo científico para una revista jurídica.

¿Cuáles son, bajo la luz de El valor del Estado y el significado del individuo, las premisas que Carl Schmitt no puede aceptar de las filosofías del derecho de Arthur Schopenhauer y Erich Jung?; ¿cuáles son las razones fundamentales del rechazo de las mismas?; ¿cómo se articulan en su crítica? Sin duda, dos ideas fundamentales de estos autores son las que merecen la ira schmittiana: por una parte, tanto en el caso de Jung como en el de Schopenhauer, la noción tecnificada del derecho y del Estado como un instrumento al servicio de los individuos; por otra, en el caso de Arthur Schopenhauer, la tesis gnóstica de la radical maldad de este mundo y del ser humano. Ambas concepciones son rechazadas frontalmente por Carl Schmitt; sin embargo, una tesis general subyace y rige la crítica que el joven jurista hace de las mismas, a saber: tanto Erich Jung como Arthur Schopenhauer no serían filósofos del derecho, sino, más bien, meros apologetas del poder y, en consecuencia, no explican nada del derecho, sino que lo niegan con sus construcciones teóricas. Empecemos por examinar esto más de cerca.

Sin duda, el argumento capital contra Schopenhauer y Jung en el artículo polémico es el siguiente: si se sigue el proceder schopenhaueriano, "no se explica la esencia del Derecho, sino que se niega"92. La razón de esta afirmación la encontramos en el dualismo poder-derecho que rige la filosofía schmittiana en estos años: como vimos, el derecho como aurora boreal, como signo de lo divino, empieza donde acaba el poder como potencia terrena; $y$ si la tarea de la filosofía del derecho es "preguntarse por el derecho del Derecho" "93 ésta debe atender exclusivamente a su naturaleza abstracta, "ideal". En esto, Carl Schmitt es tajante: "Si el Derecho pudiese ser derivado de los hechos, no existiría el Derecho. Estamos ante dos mundos situados frente a frente" ${ }^{" 94}$. Pues bien, ¿qué es lo que toman por fundamento Schopenhauer y Jung? Precisamente los hechos. La consecuencia teórica de esto es clara para Carl Schmitt:

Si el derecho es algo que está ahí [da ist, es decir, existe], estará sujeto a las leyes de la causalidad como todo lo que está ahí. Si el Derecho se vuelve poder, toda explicación que no sea causal se hunde en la nada; y toda causa que produzca efecto, se vuelve poder y, por tanto, Derecho. Por mucho que retrotraigamos el hecho en el cual el regreso al fundamento del Derecho encuentre su final, deberemos quedarnos solo con esta idea sobre esa teoría: podrá explicar o aclarar, nunca justificar o fundamentar ${ }^{95}$.

La cuestión central aquí es ésta: tal perspectiva, empleada por Schopenhauer y Jung, solo puede tener por resultado una profanación del derecho: de acuerdo con el dualismo derecho-poder schmittiano, si se concibe el derecho como

\footnotetext{
C. Schmitt, "Schopenhauers Rechtsphilosophie...”, op. cit., p. 28.

C. Schmitt, El valor ... op. cit., p. 14.

94 C. Schmitt, El valor... op. cit., p. 24. Carl Schmitt insiste en este punto: "Lo que corresponde preguntarse es si los hechos pueden fundar el Derecho. Si se responde con una negativa se establece una contraposición entre dos mundos. Se hace el Derecho autosuficiente e independiente del Poder y se sigue un dualismo que se corresponde con la antítesis entre ser y deber, entre una consideración genética y otra normativa, una científica y otra crítica" (Ibidem, p. 16).

95 C. Schmitt, El valor ... op. cit., p. 15
} 
algo que surge del ámbito terrenal del mundo, del campo de los hechos, por decirlo de una vez, del poder, entonces la teoría del derecho, en el fondo, no sería más que una teoría del poder: detrás de cualquier intento de fundamentar el derecho mediante ellos no se oculta sino "la osadía de pretender incorporar [en la fundamentación del derecho una] justificación al Poder"'96, es decir, se pretende hacer del poder derecho; y la filosofía del derecho resultante no sería más que una doctrina del Faustrecht: "Los peces grandes tienen, según el dicho popular, derecho a comerse a los chicos por la idéntica razón por la que las clases dominantes que ejercen un dominio secular sobre los habitantes de un territorio, deciden el contenido de la ley. Todos tienen derecho porque tienen poder"97. Para Carl Schmitt, es indiferente quién ostente este poder convertido en derecho: ya sea uno solo, unos pocos, o la mayoría en defensa del interés común, esto no altera en absoluto lo esencial de esta profanación: se ha negado la esencia del derecho.

A partir de aquí la crítica a Schopenhauer y Jung se dirige contra la tecnificación del derecho y del Estado, la cual se desprende inmediatamente del argumento central esgrimido contra ambos autores: "si [...] el Derecho surgiese del Poder, es decir, de simples hechos, no sería posible elevarlo por encima de lo fáctico. No cabría hablar en cualquier desarrollo jurídico de conclusiones o argumentos, solo de hechos y todo lo que se diese como «motivo» de la decisión, no constituiría más que un argumentum ab utili magníficamente formulado"98. Al tomar como punto de partida el mundo de los hechos, tanto Schopenhauer como Jung sitúan el origen del derecho en la lesión y, en consecuencia, solo pueden entender el derecho como el posterius teórico-práctico de la injusticia; y el Estado como "el remedio" coercitivo de una situación originaria de injusticia $^{99}$. Una vez definido "el Derecho como Poder dejará de ser esencialmente norma y pasará a ser fundamentalmente sólo voluntad y fin" "100; y el Estado, un mero medio de aquella voluntad. En última instancia, partir de lo fáctico es presuponer la existencia y la primacía del individuo; y tal hipervaloración del individuo conduce a una inversión del verdadero orden que ocupa respecto al derecho y al Estado.

Así, la tecnificación utilitarista del derecho y del Estado no es sino un corolario de la profanación del derecho que supone derivarlo o deducirlo del poder - en realidad, reducirlo a éste-: entender uno y otro como instrumentos al servicio del individuo (el cual más bien habría de ser "material fungible" en manos del Estado para realizar el derecho) significa denigrar su dignidad. En resumidas cuentas, de

Ibidem, p. 22

Ibidem, p. 13

Ibidem, p. 17.

99 Carl Schmitt describe la confusión que subyace a este procedimiento del siguiente modo: "El empírico que ve en el Derecho nada más que un juego de intereses y distingue solo entre intereses poderosos y dignos de protección, oculta el problema bajo una confusa ambigüedad. La palabra interés entra en contradicción con toda norma [...]; y, cuando entra en la definición de Derecho, destruye la norma (siempre por encima de cualquier interés). Cuando se define lo injusto como lesión de intereses, aparece esa lesión como algo previo. El fundamento de esa prioridad resulta de un hecho puramente empírico: ha de existir una lesión de intereses antes de que puedan los hombres pensar en protegerlos. [...]. En este tipo de argumentaciones el motivo psicológico que hace inteligible la norma se confunde con el fundamento de su validez" (C. Schmitt, El valor ... op. cit., p. 21).

100 Ibidem, p. 17. la visión tecnificada de Schopenhauer y Jung se desprende una idea de Estado como "un poder violento, brutal e irracional, del que cabría decir que consiste en una «voluntad», un terrorismo, al que nos hemos acostumbrado y que algunos saben aprovechar. Un magnum latrocinium con una meta ideal: progresar hacia una comunidad segura"101 . Este ensalzamiento de la individualidad, que Schopenhauer y Jung comparten con el liberalismo, equivale, por lo demás - esta es la metáfora jurídica que usa Schmitt-a que en un juicio la parte denunciante compareciera, también, como tribunal $^{102}$.

Junto a estas dos críticas destructivas y centrales que subyacen al artículo polémico de 1913, se deja entrever una lucha contra el enemigo último, en un sentido metafísico, de la concepción schmittiana del derecho: el gnosticismo, esta vez, encarnado en el pesimismo de Schopenhauer. Si bien en el título del artículo ya se hace hincapié en que la valoración de la filosofía del derecho de Schopenhauer se realiza frente a los esfuerzos de usarla fuera de su sistema filosófico para fundamentar el derecho, no es menos cierto que, en el interior del mismo está en juego la totalidad de la propuesta schmittiana de estos años. Desde la perspectiva de Schmitt, el núcleo de la filosofía schopenhaueriana (su pesimismo) es, a todas luces, un elemento no menos peligroso que la reducción del derecho a mero poder: no representa, ni más ni menos, que la posibilidad metafísica de esta reducción. La tesis gnóstica de que este mundo también el ser humano- es radicalmente malo (y de que la salvación solo puede ganarse con una negación igualmente radical del mismo) es el verdadero enemigo de la concepción schmittiana del derecho.

Si para la fe católica y hegeliana de Carl Schmitt Dios no puede abandonar el mundo, en la filosofia de Schopenhauer, por el contrario, Dios nunca estuvo en él. Schmitt no puede aceptar de ninguna manera el pesimismo metafísico de Schopenhauer, según el cual el pecado y el crimen son lo originario $^{103}$. El orden no puede venir del caos ni tampoco el derecho de la injusticia. El derecho no puede ser algo negativo, resultado de las peores tendencias del mundo terreno y del poder; antes bien, la tesis anti-gnóstica de Schmitt, su hegelianismo catolizado, sostiene que el poder, esta Tierra con sus fuerzas caóticas en constante pugna, aunque oscurecida por el pecado, puede quedar transfigurada en orden y ser reflejo del paraíso del derecho mediante el Estado. Así, desde el lado metafísico, la gnosis schopenhaneriana "niega la esencia del Derecho".

Estas son las razones fundamentales que empujan a Carl Schmitt a escribir contra Erich Jung y su natürliches Recht. El verdadero derecho no puede fundamentarse en una versión darwinista-schopenhaueriana del viejo ius naturale ni por su método, ni por sus resultados, ni por las tesis metafísicas que rigen, en el fondo, el ensayo junguiano (la "acrítica suposición" que hace del individuo una especie de "dios personal" ${ }^{104}$ y el schopenhaueriano (la gnosis).

\footnotetext{
1 Ibidem, p. 30.

102 Cf. Ibidem, p. 22.

103 Cf. J. L. Villacañas Berlanga, op. cit., p. 30.

104 Cf. C. Schmitt, El valor... op. cit., p. 5.
} 


\section{Bibliografía}

Balakrishnan, G., The Enemy. An Intellectual Portrait of Carl Schmitt, London/New York, Verso, 2000.

Benda, E., Das Moralistische Recht Schopenhauers als Grundlage und Quelle für inductive Rechtsfindungen, Diss., BornaLeipzig, 1913.

Bendersky, J. W., Carl Schmitt. Theorist for the Reich, New Jersey, Princeton University Press, 1983.

Bovensiepen, R., "Die Rechts- und Staatsphilosophie Schopenhauers", en Zeitschrift für die gesamte Staatswissenschaft, 71, 1915, pp. 183-216.

Damm, O., Schopenhauers Rechts-und Staatsphilosophie. Darstellung und Kritik, Halle, Kaemmerer, 1900.

Emerson, R., State and Sovereignty in Modern Germany, New Haven, Yale University Press, 1928.

Flack, N. N., Juristische Encyklopädie, auch zum Gebrauch bei akademischen Vorlesungen, Leipzig, Böhmberg, 1839.

Groh, E., Carl Schmitts gnostischer Dualismus. Der boshafte Schöpfer dieser Welt hat es so eingerichtet (...), Berlin, Lit Verlag, 2014.

Hernández Marcos, M., "Conocimiento racional e historia. Sobre la relación entre derecho natural y derecho positivo en la Codificación Prusiana de 1794”, en A. Prior Olmos (ed.), Estado, Hombre y Gusto Estético en la Crisis de la Ilustración, Valencia, Biblioteca Valenciana, 2003, pp. 167-181.

Jellinek, G., Die Weltanschauungen Leibnitz' und Schopenhauers. Ihre Gründe und ihre Berechtigung. Eine Studie über Optimismus und Pessimismus, Wien, Alfred Hölder, 1872.

Jung, E., Das Problem des natürlichen Rechts, Leipzig, Duncker \& Humblot, 1912.

Jungcurt, U., Alldeutscher Extremismus in der Weimarer Republik. Denken und Handeln einer einflussreichen bürgerlichen Minderheit, Berlin/Boston, Gruyter, 2016.

Kennedy, E., Constitutional Failure. Carl Schmitt in Weimar, Durham/London, Duke University Press, 2004.

Klee, E., Das Personenlexikon zum Dritten Reich. Wer war was vor und nach 1945?, Frankfurt am Main, Fischer, 2003.

Krug, W. T., Allgemeines Handwörterbuch der philosophischen Wissenschaften, nebst ihrer Literatur und Geschichte. Nach dem heutigen Standpuncte der Wissenschaft. Bd. 3, Leipzig, Brockhaus, 1828.

Meierhenrich, J. y Simons, O. (eds.), The Oxford Handbook of Carl Schmitt, New York, Oxford University Press, 2016.

Orestes Aguilar, H., Carl Schmitt, teólogo de la politica, México, F.C.E., 2001.

von der Pfordten, Th., Staat und Recht bei Schopenhauer, München-Berlin-Leipzig, J. Schweitzer, 1916.

Schmitt, C., Catolicismo romano y forma politica, Madrid, Tecnos, 2000.

-, El concepto de lo político, Madrid, Alianza, 1998.

-, El valor del Estado y el significado del individuo, trad. C. Pardo, Madrid, Centro de Estudios Políticos y Constitucionales, 2014.

-, Ex captivitate salus. Experiencias de la época 1945-1947, trad. A. Schmitt de Otero, Madrid, Trotta, 2010.

-, Glossarium. Aufzeichnungen aus den Jahren 1947 bis 1958, Berlin, Duncker \& Humblot, 2015.

-, "La visibilidad de la Iglesia. Una reflexión escolástica" trad. R. García Pastor, Daimon. Revista internacional de filosofía 13, 1996, pp. 11-18.

-, "Schopenhauers Rechtsphilosophie außerhalb seines philosophisches Systems", Monatsschrift für Kriminalpsychologie und Strafrechtsreform X, 1, abril, 1913, pp. 27-31.

-, Tagebücher. Oktober 1912 bis Februar 1915, hrsg. Ernst Hüsmert, Berlin, Akademie Verlag, 2005.

Schopenhauer, A., El mundo como voluntad y representación. Volumen I, trad. R. Rodríguez Aramayo, Madrid, F.C.E./Círculo de Lectores, 2003.

-, El mundo como voluntad y representación, volumen II, trad. R. Rodríguez Aramayo, Madrid, F.C.E./Círculo de Lectores, 2003.

-, Los dos problemas fundamentales de la ética, trad. P. López de Santa María, Madrid, Siglo XXI, 2009.

-, Metafísica de las costumbres, trad. R. Rodríguez Aramayo, Madrid, Trotta, 2001.

-, Parerga y paralipómena, volumen II, trad. P. López de Santa María, Madrid, Trotta, 2009.

Stock, G., Abriß eines Systems der Erscheinungen des Rechtslebens an der Hand der philosophischen Methode Schopenhauers, Diss., Marburg, 1922.

Villacañas Berlanga, J. L., Poder y conflicto. Ensayos sobre Carl Schmitt, Madrid, Biblioteca Nueva, 2008.

VV.AA., Rechtslexikon für Juristen aller teutschen Staaten enthaltend die gesammte Rechtswissenschaft. Bd. 9, Hrsg. J. Weiske, Leipzig, Otto Wigand, 1855.

de Warren, N. y Stati, A. (eds.), New Approaches to Neo-Kantianism, Cambridge, Cambridge University Press, 2015.

Warschauer, E., Schopenhauers Rechts- und Staatslehre, Kattowitz, Gebrüder Böhm, 1911.

Weigt, K., Die politischen und sozialen Anschauungen Schopenhauers, Diss., Erlangen, 1899. 